\title{
A time motion study to evaluate the average waiting time in OPD with reference to patient satisfaction in the setting of state-level AYUSH Hospital (India)
}

\author{
Farah NAAZ1', Idris MOHAMMED² \\ ${ }^{1}$ Pharmacopoeia Commission for Indian Medicine and Homoeopathy, India \\ ${ }^{2}$ Ayurvedic and Unani Tibbia College, India. \\ Correspondence \\ Farah NAAZ \\ Pharmacopoeia Commission for Indian Medicine and Homoeopathy, India \\ e-mail:farah.ali07@gmail.com
}

\begin{abstract}
The outpatient department (OPD) is the first point of contact of a hospital with patients and serves as the shop window of the hospital. The care in the OPD indicates the quality of services provided by the hospital and is reflected by patient satisfaction. Overcrowding contributes significantly to patient dissatisfaction because of the long waiting and less consultation time. Data on the services of AYUSH systems in India are scarce, although AYUSH systems are now a part of the national health-care delivery structure. Therefore, this study aimed to investigate the services rendered by the AYUSH hospitals to understand the lacunae, help improve the system, and increase the accessibility among the masses.

A time-motion study (TMS), including 100 patients from the state-level AYUSH Hospital, New Delhi, was conducted to assess the average waiting time of patients and the level of satisfaction of patients in terms of services provided by the hospital.

The duration of this study was 15 working days. The data were gathered by TMS and direct patient interviews.

The findings revealed that, on average, a patient spent nearly $2 \mathrm{~h}$ in the OPD from its arrival to exit. The major reason for this prolonged waiting time was the time for consultation, which was $1 \mathrm{~h} 10 \mathrm{~min}$, and almost 16 min at the pharmacy. Moreover, the average time a patient spent with the doctor for consultation was $3 \mathrm{~min}$.

In conclusion, the patients were least satisfied by the OPD waiting time, consultation time, and pharmacy services.
\end{abstract}

Key words: AYUSH Services, ISM and H, OPD, patient satisfaction, time-motion study, TMS

\section{INTRODUCTION}

ISM and $\mathrm{H}$ stands for Ayurveda, Yoga, and Naturopathy, Unani, Siddha, and Homoeopathy jointly referred to as AYUSH in India. Today AYUSH is an integral part of the national health-care delivery structure. AYUSH systems need a three-dimensional strengthening as defined in the National Health Policy 2017 [1]. Evidence on the use of traditional medical services comes from small-area studies. Only a few studies are based on a sample large enough to generate any evidence. Clearly, a more systematic analysis should be undertaken to examine AYUSH care utilization across regional, socioeconomic, and demographic groups [2].

The waiting time at the outpatient department (OPD) is an important determinant of quality services as it is noted that in health-care provision "delays are expensive, not only in terms of direct costs incurred, but also in terms of the potential costs of decreased patient satisfaction and adverse outcomes" [3]. The Institute of Medicine recommended that at least $90 \%$ of the patients should be seen within 30 min of their scheduled appointment [4]. This is, however, not the case in most developing countries, as several studies showed that patients spent $2-4 \mathrm{~h}$ in the OPDs before seeing a doctor. A source of dissatisfaction with health care reported by patients was having to wait for a long time in the clinic. Several studies documented the negative association between increased waiting time and patient satisfaction with primary care [5].

Therefore, the present study aimed to investigate the average time consumed by patients at various counters while availing services in the OPD of an AYUSH Hospital. 


\section{MATERIALS AND METHODS}

\section{Study area}

This study was carried out in the OPD of Ayurvedic and Unani Tibbia College and Hospital Block, run by the Government of National Capital Territory (NCT), Delhi, located at Karol Bagh, New Delhi (India). It is one of the four AYUSH Hospitals run by the state government in Delhi. The Ayurvedic and Unani Tibbia College and Hospital has a bed capacity of 200 beds that attends to more than 100,000 outpatients in a year. The hospital also has an attached 50-bedded maternity center. It has six departments/OPDs in Ayurvedic medicine, six departments/OPDs in Unani medicine, one OPD for homeopathy medicine, and one OPD for the Sidhha system of medicine. The hospital has a fully established pathology laboratory and a radiology department.

\section{Study population}

The study population included all patients seeking care at the OPD of Ayurvedic and Unani Tibbia College and Hospital.

\section{Study design}

A descriptive cross-sectional study was conducted in April-May, 2018, on patients seeking treatment in the state-level AYUSH Hospital of Delhi.

\section{Methods}

Using a convenient sampling technique, about 100 patients were selected for the time-motion study (TMS) and then interviewed using a pretested semistructured questionnaire to collect data regarding patient satisfaction. Data entry and analysis were done using Microsoft Excel 2010. Percentages and proportions were calculated for descriptive statistics. For TMS, time was noted with the help of a digital stopwatch and detected at each and every station by an observer with the help of the same watch. The time difference was calculated and analyzed for every station.

\section{OBSERVATIONS AND RESULTS}

Most of the study population (35\%) belonged to the 31 - to 40 -year age group; of these, $56 \%$ were male. The maximum percentage (33\%) of the study population had a monthly income between 10,001 and 20,000 INR. Most of the study population (34\%) completed primary education, and $26 \%$ were self-employed (Table 1). The utilization of services by patients attending the state-level AYUSH Hospital was also investigated. The maximum number of patients opted for Ayurvedic treatment (44\%) followed by Unani medicine, which was sought by $38 \%$ of patients. Ho-

Table 1 Distribution of respondents according to sociodemographic characteristics $(n=100)$

\begin{tabular}{|c|c|}
\hline Sociodemographic characteristic & Percentage (\%) \\
\hline \multicolumn{2}{|l|}{ Age (in year) } \\
\hline $18-20$ & 13 \\
\hline $21-30$ & 23 \\
\hline $31-40$ & 35 \\
\hline $41-50$ & 13 \\
\hline $51-60$ & 11 \\
\hline+61 & 5 \\
\hline \multicolumn{2}{|l|}{ Sex } \\
\hline Male & 56 \\
\hline Female & 44 \\
\hline \multicolumn{2}{|l|}{ Marital status } \\
\hline Single & 23 \\
\hline Married & 63 \\
\hline Widowed/Separated & 14 \\
\hline \multicolumn{2}{|l|}{ Education } \\
\hline Illiterate & 9 \\
\hline Primary & 34 \\
\hline Secondary & 16 \\
\hline High school & 28 \\
\hline Graduate or above & 13 \\
\hline \multicolumn{2}{|l|}{ Occupation } \\
\hline Unemployed & 0 \\
\hline Government employed & 3 \\
\hline \multicolumn{2}{|l|}{ Non-government employed/ } \\
\hline Self-employed & 25 \\
\hline Labor & 33 \\
\hline Student & 13 \\
\hline Housewife & 26 \\
\hline
\end{tabular}

Income

(Avg. monthly income of head of the family in INR)

$\begin{array}{ll}\text { Above } 100,000 & 0 \\ 50,001-100,000 & 0 \\ 20,001-50,000 & 7 \\ 10,001-20,000 & 33 \\ 7501-10,000 & 31 \\ 5001-7500 & 19 \\ \text { Up to } 5000 & 10\end{array}$




\section{AYUSH System}

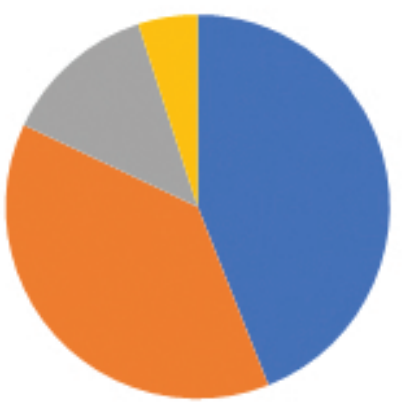

- Ayurveda
- Unani
Womeopathy
- Siddha
- Yoga

Figure 1 Distribution of respondents according to the AYUSH service utilization $(n=100)$.

meopathy medicine was the choice of $13 \%$ of patients, followed by $5 \%$ of patients opting for Siddha medicine (Figure 1). The mean waiting time at the registration counter for the process of registration and obtaining OPD slip was calculated to be 10 min $36 \mathrm{~s}$. The mean waiting time at OPD waiting lounge from arrival to entry in OPD for consultation was calculated to be $1 \mathrm{~h} 10$ min $38 \mathrm{~s}$, whereas the mean time for OPD consultation, that is, the time given by doctors to each patient was calculated to be 3 min $22 \mathrm{~s}$ only. On average, a patient spent about 16 min $43 \mathrm{~s}$ in the pathology lab and $23 \mathrm{~min} 37 \mathrm{~s}$ in the radiology department. However, the average time consumed by each patient at the pharmacy counter was $13 \mathrm{~min} 53 \mathrm{~s}$. On average, a patient spent $2 \mathrm{~h} 17 \mathrm{~min} 29 \mathrm{~s}$ from his/her arrival in the hospital to exit from the OPD (Table 2 and Figure 2).

When the patients were asked about their experience at the registration counter, only $13 \%$ replied "poor," whereas when asked to give feedback on time consumed in the queue at the registration counter, maximum number $(47 \%)$ of patients responded "normal," $8 \%$ patients said it was unbearable to stand in

Table 2 Study of time required in different point of channelization process to access the OPD services $(n=100)$

\begin{tabular}{ll}
\hline Channelization point & Average time (h:min:s) \\
\hline Registration counter & $0: 10: 36$ \\
OPD & $1: 10: 38$ \\
Consultation room & $0: 3: 22$ \\
Pathology lab & $0: 16: 43$ \\
Radiology lab & $0: 23: 37$ \\
Pharmacy & $0: 13: 53$ \\
Total overall mean time required to get OPD services after joining the queue & $2: 17: 29$ \\
\hline
\end{tabular}

\section{Average Time (min)}

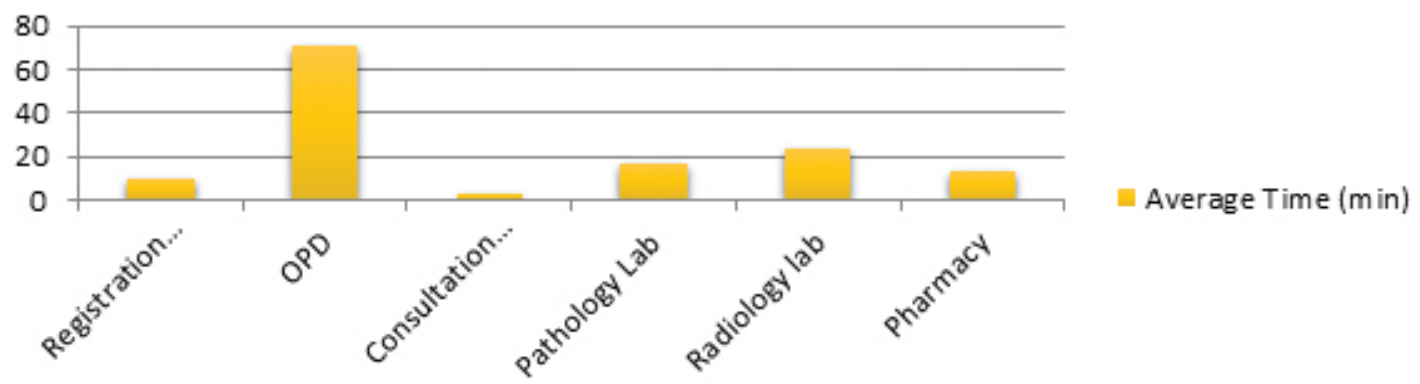

Figure 2 Study of time required in different point of channelization process to access the OPD services $(n=100)$ 
the queue, and none said it was fast. When patients were asked to give their response on the waiting time in the OPD, the maximum number (40\%) of patients said it was very slow, $28 \%$ replied "slow," $17 \%$ replied "unbearable," and only $15 \%$ replied "normal." In contrast, when patients were asked to give their response about the time given by the doctor for consultation in the OPD, the maximum number (37\%) of patients replied normal, $29 \%$ replied sufficient, $17 \%$ replied less, and $13 \%$ replied very less. When asked about the waiting time in the pharmacy, only $9 \%$ of patients said that it was very less and $22 \%$ agreed that sufficient time was given by pharmacists to explain the medicines and dosage. Patients replied that the waiting time in the pathology lab and radiology lab was normal according to their perception. When patients were asked to give their feedback about their experience on the overall waiting time in getting OPD services at the hospital, the maximum number (49\%) of patients said that it was good, $24 \%$ replied very good, $7 \%$ replied excellent, and $20 \%$ replied poor or very poor (Table 3).

Table 3 Study of patient satisfaction by feedback questionnaire/exit interview

\begin{tabular}{|c|c|c|c|c|c|c|}
\hline S. & Question & \multicolumn{5}{|c|}{ Response $(n=100)$} \\
\hline \multirow{2}{*}{1} & \multirow{2}{*}{$\begin{array}{l}\text { How was your experience in the queue at the registration } \\
\text { counter? }\end{array}$} & Very poor & Poor & Good & Very good & Excellent \\
\hline & & 0 & 13 & 41 & 27 & 19 \\
\hline \multirow{2}{*}{2} & \multirow{2}{*}{ How was the time taken in registration queue? } & Very quick & Normal & Slow & Very slow & Unbearable \\
\hline & & 0 & 47 & 27 & 19 & 7 \\
\hline \multirow{2}{*}{3} & \multirow{2}{*}{ How was the queue at Registration counter? } & Fast & Normal & Slow & Very slow & Unbearable \\
\hline & & 0 & 46 & 27 & 19 & 8 \\
\hline \multirow{2}{*}{4} & \multirow{2}{*}{$\begin{array}{l}\text { How was your experience regarding time taken during waiting } \\
\text { at OPD? }\end{array}$} & Quick & Normal & Slow & Very slow & Unbearable \\
\hline & & 0 & 15 & 28 & 40 & 17 \\
\hline \multirow{2}{*}{5} & \multirow{2}{*}{ How was the turn of OPD consultation? } & Quick & Normal & Slow & Very slow & Unbearable \\
\hline & & 0 & 17 & 26 & 39 & 18 \\
\hline \multirow[t]{2}{*}{6} & \multirow[t]{2}{*}{ How much time for consultation by the doctor has been given? } & Very less & less & Normal & Sufficient & $\begin{array}{l}\text { More than } \\
\text { Sufficient }\end{array}$ \\
\hline & & 13 & 17 & 37 & 29 & 4 \\
\hline \multirow{2}{*}{7} & \multirow{2}{*}{ How much time was consumed at the pharmacy counter? } & Very less & less & Normal & Much & Very much \\
\hline & & 9 & 14 & 43 & 19 & 15 \\
\hline \multirow[t]{2}{*}{8} & \multirow{2}{*}{$\begin{array}{l}\text { How much time was given by the pharmacist to explain dose } \\
\text { and method of drug intake? }\end{array}$} & Very less & less & Normal & Sufficient & $\begin{array}{l}\text { More than } \\
\text { sufficient }\end{array}$ \\
\hline & & 34 & 22 & 28 & 16 & 0 \\
\hline \multirow[b]{2}{*}{9} & \multirow{2}{*}{$\begin{array}{l}\text { Whether any pathological investigation was advised to you by } \\
\text { the consulting doctor? If yes, how was your experience in the } \\
\text { lab in terms of waiting time? }\end{array}$} & Very less & less & Normal & Much & Very much \\
\hline & & 0 & 15 & 45 & 22 & 18 \\
\hline \multirow[b]{2}{*}{10} & \multirow{2}{*}{$\begin{array}{l}\text { Whether any x-ray was advised to you by the consulting } \\
\text { doctor? If yes, how was your experience in the x-ray } \\
\text { department in terms of waiting time? }\end{array}$} & Very less & less & Normal & Much & Very Much \\
\hline & & 0 & 0 & 69 & 20 & 11 \\
\hline \multirow{2}{*}{11} & \multirow{2}{*}{$\begin{array}{l}\text { How was your overall experience in the hospital in terms of } \\
\text { waiting time at various places since your arrival? }\end{array}$} & Very poor & Poor & Good & Very good & Excellent \\
\hline & & 5 & 15 & 49 & 24 & 7 \\
\hline
\end{tabular}




\section{DISCUSSION}

The health status of Indian people and the factors affecting the status and health-care services in India are fast becoming issues of great concern in the changing national and international social and economic scenarios. The public health-care system that currently exists in rural India, where $68.84 \%$ of the population lives, is largely dysfunctional (Census report, 2011). As a result, more policies and programs are being initiated by the Government of India, where AYUSH services are being used to provide health needs to the population. Therefore, it becomes essential to study their organization and management so that lacunae in the implementation process can be removed. In the aforementioned context, this study was undertaken to generate information that would improve the efficiency of operations and quality of service delivery at the AYUSH hospitals.

In this study, a majority of the patients attending the OPDs were in the age group of 31-40 years (35\%); $58 \%$ accounted for patients in the age group of 21-40 years. The number of male patients was higher (56\%) than that of female patients (44\%). The findings of this study were consistent with those of the study conducted by Shukla et al. in Madhya Pradesh, which showed that $59 \%$ of the patients were male, $41 \%$ were female, and the majority of patients belonged to the age group of 16--40 years (49\%) [6]. In the present study, $34 \%$ of patients had a primary level of education and only $13 \%$ of patients were graduates and above. These results were comparable to the study conducted by Patel et al. in Gujrat [49]. In the present study conducted at the AYUSH Hospital, most of the attending patients were laborers, with most having an average monthly income between 10,001 and 20,000 INR. From the aforementioned findings, it was inferred that the AYUSH health services were most utilized by the lower class of the society; the reason might be the free health services available at the large 200-bedded hospital.

From the present study, it was inferred that Ayurveda was the preferred system of medicine among all the AYUSH systems, followed by Unani, homeopathy, and Siddha medicines. The findings of the present study were comparable with the results of the study conducted by Anandaraj et al. at the District AYUSH Hospital in Karnataka [7].
- In the present study, the mean waiting time at the registration counter was found to be around 10 min, whereas it was approximately $1 \mathrm{~h}$ at the OPD waiting lounge. The mean time given by the doctors to each patient was calculated to be only $3 \mathrm{~min}$. The mean time at the pharmacy counter was about 13 min. The present study revealed that, on average, a patient spent nearly $2 \mathrm{~h}$ for getting OPD services from his/her arrival in the hospital to exit from the OPD. Data for comparison are lacking because very few similar studies have been conducted. However, the data generated were consistent with the results of the study conducted by Javed at the state-level Ayurvedic hospital in Delhi [8].

The present study attempted to assess the level of satisfaction of the patients with regards to AYUSH OPD services in particular and AYUSH health services in general provided at the state-level AYUSH Hospital in Delhi. The results of the study indicated that most of the respondents interviewed were satisfied with the services they received. Data for comparison are lacking because a very few similar studies have been conducted. Measuring patient satisfaction has many purposes. Such interviews help to evaluate healthcare services from the patient's point of view, facilitate the identification of problematic areas, and help generate ideas toward resolving these problems. Despite a good level of patient satisfaction, a small, but by no means, insignificant proportion of patients expressed the least satisfaction toward certain OPD services. This dissatisfaction indicated that hospital administration needed to do more in ${ }^{* * *}$ the drive toward improving services.

In view of the aforementioned discussion, the study suggested the following ways to decrease patient dissatisfaction:

- The hospital may improve on the signage system. More defined and user-friendly signages should be used with pictorial description for guiding illiterate patients. This will help in reducing the congestion in the corridors.

- The hospital can have the facility to increase the registration counters during the busy hours.

- A proper fixed time slot should be established for visiting medical representatives. 
- Facilities such as drinking water and washrooms should be improved as these are the areas gravely concerning patients' satisfaction.

- A proper token system should be followed to reduce the waiting time and chaos in the queues.

- Patients may be guided about by the preventive aspects of common diseases by means of videos while waiting in the OPD block.

- Doctors and nurses should also be oriented time to time to provide better consultation and care to the patients. In OPDs with a maximum number of patients in a day, interns may be allowed to support, such as in taking vitals and history.

\section{CONCLUSIONS}

The present study has brought to the surface certain gray areas to which the hospital needs to pay attention. Patient satisfaction is an important indicator that reflects the service quality at any level of health services. Many factors are responsible for patient dissatisfaction, such as queuing time, waiting time, physical facility available at OPD registration counter area, and lack of proper signage system. Overall, the study showed a good level of satisfaction of patients with OPD services obtained from this state-level AYUSH Hospital. In this study, patients were least satisfied by the OPD waiting time, consultation time, and pharmacy services. Also, effective communication with the patients about their disease and the treatment, which is largely ignored, and the most efficient preventive measures to allay their fears, remove misconceptions, comply with the treatment, and develop confidence in the AYUSH health system are urgently needed for achieving the standards of good health. These leastsatisfied services should be considered as points for improvement in the overall satisfaction level.

Sources of Funding: None

Conflicts of interest: None

\section{REFERENCES}

1. National Health Policy 2017. http://www.cdsco.nic.in/ writereaddata/National-Health-Policy.pdf

2. Government of India. Annual Report 2014 \pm 15 [Internet]. New Delhi: Ministry of Ayurveda, Yoga \& Naturopathy, Unani, Siddha and Homoeopathy (AYUSH); 2015. http://ayush.gov. in/sites/default/files/AYUSH\%20ENGLISH\%20ANNUAL\%20 REPORT-2014-15.pdf

3. Haussmann, R. K. Waiting time as an index of quality of nursing care, Health service research, McKinsey and Company, New York.1970; 93-105.

4. Srinivasan P. National Health Policy for Traditional Medicine in

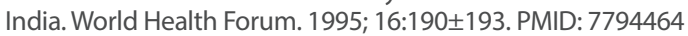

5. Jaggi OP. Medicine in India: modern period. Oxford University Press, 2000.

6. Shukla Y, Tiwari R, Rohit B K \&Kasar P K. An assessment of OPD registration counters services and channelization of patients in NSCB Medical College Hospital, Jabalpur (MP). Int J Med Sci Public Health. 2015; 4(10): 1468-1472.

7. Anandaraj R, Raghavendra SK, Kavithai P, Manu A. A Study of Service Utilization and Client Satisfaction among Patients Attending a District Ayush Hospital in Karnataka. Journal of Dental and Medical Sciences. 2017; 16(1):10-13.

8. Javed D. A Time-Motion Study of OPD Services at a State Level Ayurvedic Hospital to reduce the OPD Congestion. IAMJ. 2015; 3(10):1-9. 